\title{
The impact of pretreatment with simvastatin on kidney tissue of rats with acute sepsis
}

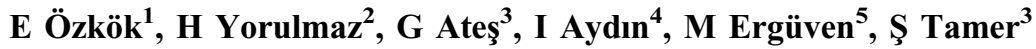 \\ ${ }^{1}$ Deparment of Neuroscience, The Institute of Experimental Medicine, Istanbul University, Istanbul, Turkey \\ ${ }^{2}$ Medical Faculty, Haliç University, Istanbul, Turkey \\ ${ }^{3}$ Department of Physiology, Istanbul Medical Faculty, Istanbul University, Istanbul, Turkey \\ ${ }^{4}$ Medical Laboratory Techniques Department, Associate's Degree Vocational School, Beykent University, Istanbul, \\ Turkey \\ ${ }^{5}$ Faculties of Engineering and Health Sciences, Istanbul Aydın University, Istanbul, Turkey
}

Received: May 31, 2016

Accepted: April 21, 2017

\begin{abstract}
It has been reported that changes in cytokine levels affect mitochondrial functions, levels of hypoxia-inducible factor $\alpha$ (HIF-1 $\alpha$ ), and tissue damage during sepsis. We aimed to investigate the effects of simvastatin pretreatment on mitochondrial enzyme activities, and on levels of ghrelin, HIF-1 $\alpha$, and thiobarbituric acid reactive substances (TBARS) in kidney tissue during sepsis. Rats were separated into four groups, namely, control, lipopolysaccharides (LPS) $(20 \mathrm{mg} / \mathrm{kg})$, simvastatin $(20 \mathrm{mg} / \mathrm{kg})$, and simvastatin + LPS. We measured the levels of mitochondrial enzyme activities and TBARS in the kidney using spectrophotometry. The histological structure of the kidney sections was examined after staining with hematoxylin and eosin. Tumor necrosis factor $\alpha$ (TNF- $\alpha$ ), IL-10, HIF-1 $\alpha$, and ghrelin immunoreactivity were examined using proper antibodies. In tissue, TNF- $\alpha(p<0.01)$ and HIF-1 $\alpha(p<0.05)$ levels were increased in the simvastatin + LPS and LPS groups. TBARS levels were higher in the LPS group than in the other groups $(p<0.01)$, but they were similar in the simvastatin + LPS and control groups $(p>0.05)$. Ghrelin immunoreactivity was lower in the LPS group $(p<0.05)$ and higher in the simvastatin + LPS group than in the LPS group $(p<0.01)$. We observed tubular damage in the sections of the LPS group. There were no differences in mitochondrial enzyme activities between the groups $(p>0.05)$. We observed that pretreatment of simvastatin caused favorable changes on ghrelin and TBARS levels in rats with sepsis.
\end{abstract}

Keywords: hypoxia-inducible factor, ghrelin, kidney, lipopolysaccharides, sepsis, simvastatin

\section{Introduction}

Sepsis is a common and often devastating condition characterized by uncontrolled infection and multisystem organ failure (40). Acute kidney injury (AKI) incidence is about $40 \%$ in patients with severe sepsis and septic shock. Within the kidney, there are multiple levels at which significantly different changes might occur. These include alterations in renal blood flow, glomerular and peritubular microcirculation, tubular cell function, and structure (6). Lipopolysaccharides (LPS) can lead to septic shock characterized by endothelial damage, loss of vascular tone, coagulopathy, and multiple system organ failure, which often result in death. Moreover, LPS induces the occurence of inflammatory reactions with the release of cytokines, complement factors, and increments of reactive oxygen species (ROS) (41). It has been demonstrated that increased ROS affects the structure of renal tubular cells by inducing

\footnotetext{
Corresponding author: Assoc. Prof. Hatice Yorulmaz

Medical Faculty, Haliç University

Sütlüce Mah. İmrahor Cad. No: 82, Beyoğlu, Istanbul 34445, Turkey

Phone: +90 2129242444; Fax: +90 2129997852; E-mail: haticeyorulmaz@hotmail.com
} 
lipid peroxidations of the cell membrane, and oxidation of proteins, carbohydrates, and DNA molecules (3).

The role of tumor necrosis factor $\alpha(\mathrm{TNF}-\alpha)$ has been shown to be pivotal in the inflammatory response in endotoxemia-related AKI. During sepsis, TNF- $\alpha$ mediates the release of pro-inflammatory cytokines with anti-inflammatory mediators, such as IL-1Ra, IL4, IL10, and IL13 (4). LPS inhibits respiration by mitochondria in vivo and in vitro (15). Pathologies such as ultrastructural mitochondrial alterations and oxidative mechanisms in sepsis and septic shock have attracted attention in recent years (8).

Mitochondrial dysfunction has been suggested to contribute to the development of organ dysfunction and failure in sepsis. The mitochondrial electron transport chain consists of four complexes (CI-CIV) and its function can be assessed with different approaches (16). It has been shown that excessive production of cytokines caused alterations of oxygen consumption and mitochondrial complexes, and these changes contributed to mortality during sepsis (32). Treatment of macrophages with LPS can increase the expression of a number of hypoxic genes. Hypoxia-inducible factor $\alpha$ (HIF-1 $\alpha)$ is recognized as a mediator that allows for cellular adaptation and energy homeostasis at low oxygen concentrations (42).

Statins, such as simvastatin and atorvastatin, possess pleiotropic effects, including antioxidant and anti-inflammatory properties (22). In particular, the anti-inflammatory properties correlate with reduced sepsis-induced morbidity and mortality. However, there is no consensus in the literature for this protective effect, as some studies drew attention to the lack of randomized controlled trials in these earlier reports. Studies have also demonstrated that statins have an adverse effect on sepsis $(29,33)$. Ando et al. (2) reported that pretreatment with statins improved survival in a murine sepsis model. In the literature, the useful effect of statins has been shown in sepsis-induced AKI in an experimental model (30). In addition, in vitro and in vivo studies have demonstrated that simvastatin has an anti-inflammatory effect in patients with pre-dialytic chronic kidney disease, and may play an important role in counteracting the mechanisms involved in the pathogenesis of inflammation (25).

Ghrelin has anti-inflammatory properties and its receptors are widely expressed throughout the body. It has been shown that ghrelin levels decreased during sepsis and ghrelin administration protected against organ damage by preventing the release of norepinephrine and pro-inflammatory cytokines in rats with sepsis (36).

We aimed to investigate the effects of pretreatment with simvastatin on mitochondrial enzyme activities, and on levels of thiobarbituric acid reactive substances (TBARS) as end products of lipid peroxidation, HIF-1 $\alpha$, and ghrelin in kidney tissue during early-phase sepsis.

\section{Materials and Methods}

\section{Experimental groups}

This study was conducted at the Istanbul University experimental research center, (resolution no: 2012/138). We used male adult Wistar albino rats that weighed $200-250 \mathrm{~g}$ as experimental models. The rats were fed a commercial diet and tap water ad libitum. They were housed in cages and maintained at a controlled temperature $\left(22 \pm 2{ }^{\circ} \mathrm{C}\right)$ and humidity (55-60\%) with a 12-h light/dark cycle.

The rats were divided into four groups, each comprised eight rats: (1) control group $(n=8),(2)$ LPS group $(n=8),(3)$ simvastatin group $(n=8)$, and (4) simvastatin + LPS group $(n=8)$. 


\section{Experimental procedures}

LPS from Escherichia coli O127:B8 (Sigma Aldrich, Product No: L5668) was intraperitoneally injected at a dosage of $20 \mathrm{mg} / \mathrm{kg}$; and simvastatin $(20 \mathrm{mg} / \mathrm{kg}$ ) (Lactone form, Sigma Aldrich, Product No: S0650000) was dissolved in physiological saline and provided through oral gavage for 5 days (7). In the simvastatin + LPS-treated group, LPS was provided $1.5 \mathrm{~h}$ after the fifth dosage of simvastatin. All rats treated with LPS were sacrificed after $4 \mathrm{~h}$.

\section{Histological procedures}

The kidney tissue samples were fixed in $10 \%$ buffered formalin and embedded in parafin wax. Five-micrometer-thick sections were placed on polylysine-coated slides and stained with hematoxylin and eosin (H\&E). The slides were evaluated under light microscopy (Olympus BX51; Olympus Corp., Tokyo, Japan) at 40× magnification.

\section{Immunohistochemical procedures}

A total of 8 slides for each group were then incubated with primary antibodies: TNF- $\alpha(1: 100$; NBP1-47581, Novus, USA), HIF-1 $\alpha$ (1:100; NB100-479, Novus, USA), IL-10 (1:100; ARC0102, Invitrogen, USA), and ghrelin (1:100; NBP1-51224, Novus, USA) for $1 \mathrm{~h}$ at $37^{\circ} \mathrm{C}$. The slides were then incubated with the secondary antibody (859043 Histostain-Plus Kit, Invitrogen, USA) at $37^{\circ} \mathrm{C}$ for $30 \mathrm{~min}$, washed with a phosphate-buffered saline buffer, and 3-amino-9-ethylcarbazole (AEC) (2007, AEC reagent set, Invitrogen) staining was applied. The sections were counterstained with Mayer's hematoxylin (MHS16, SigmaAldrich, USA) (9). All sections were photographed using an Olympus C-5050 digital camera. For each specimen, a score was assigned according to the percentage of positive cells: $<5 \%$ of the cells: 1 point; $6-35 \%$ of the cells: 2 points; $36-70 \%$ of the cells: 3 points; and $>71 \%$ of the cells: 4 points. The percentage indicated how many cells out of 100 had stained positive for the targeted protein per area. The intensity of staining was also quantified, with negative staining equal to 1 point; weak staining, 2 points; moderate staining, 3 points; and strong staining, 4 points. The expression score was then calculated by multiplying the two scores above (23).

\section{TBARS}

The levels of kidney TBARS were determined using a thiobarbituric acid assay (TBA) (5). Tissue homogenates were reacted with TBA reagent that contained trichloroacetic acid and $\mathrm{HCl}$, boiled for $15 \mathrm{~min}$, cooled, and then centrifuged. Absorbances of the supernatants were spectrophotometrically measured at $532 \mathrm{~nm}$. TBARS concentrations were calculated using 1,3,3,3 tetraethoxypropane as a standard. The results were expressed as nmol/g tissue (5).

\section{Mitochondrial enzyme activities}

The absorbances of all activities were kinetically recorded using a spectrophotometer (Shimadzu, Japan) at $30{ }^{\circ} \mathrm{C}$. Citrate synthase activity was initiated by adding of dithiobis 2-nitrobenzoic acid into a mixture containing oxaloacetate, acetyl-CoA, and tissue homogenate. The absorbance was measured at $412 \mathrm{~nm}$. Complex I [nicotinamide adenine dinucleotide (NADH) dehydrogenase oxidation of NAD] activity was first monitored using potassium phosphate, NADH, and potassium ferricyanide, and then by adding tissue homogenate at $340 \mathrm{~nm}$. The tissue homogenate for complex II + III (succinate-cytochrome c reductase) was added to a mixture of fresh cytochrome c containing succinate, and potassium cyanide $(\mathrm{KCN})$. Complex II + III activity was observed as the increase in rate of reduction of 
cytochrome c. This was measured at $550 \mathrm{~nm}$ (18). Complex I + III (NADH-cytochrome c reductase) activity was observed as a result of the rate of decrease in the addition of cytochrome c homogenate, which included freshly prepared cytochrome c, NADH, and $\mathrm{KCN}$ alterations after adding rotenone at $550 \mathrm{~nm}$ (31). Complex II (succinate dehydrogenase) activity was determined through the reduction of 2,6-dichlorophenolindophenol at $600 \mathrm{~nm}(18)$.

\section{Statistical analysis}

Data were expressed as mean \pm standard deviation. Tukey's test was used to test the differences among means for which ANOVA indicated significant for TBARS levels and mitochondrial enzyme activites $(p<0.05)$. The results of immunohistochemistry analysis were statistically analyzed using Student's $t$-test. The data were represented as mean \pm standard error of the mean. $p<0.05$ was considered to be statistically significant.

\section{Results}

\section{Histological findings}

We observed dilatation of tubule lumens and partial damage to the epithelial cells in the LPS group. The tubule structures in the simvastatin group were found to resemble those in the controls' sections. The tubule dilatation and proximal cell damage were observed in the simvastatin + LPS group (Fig. 1A-D).

\section{Immunohistochemistry findings}

As shown in Table I, there was increased TNF- $\alpha$ in the LPS and simvastatin + LPS groups ( $p<0.01$ for both groups) (Fig. 2A-D) and HIF-1 $\alpha$ levels $(p<0.05$ for both groups) (Fig. 3A-D) in the LPS and simvastatin + LPS groups compared with the control group $(p<0.05)$. Although there was increased IL-10 immunoreactivity in the LPS and simvastatin + LPS groups, we found no statistically significant differences $(p>0.05)$ (Fig. 4A-D). Ghrelin immunoreactivity was decreased in the LPS group compared with the controls $(p<0.05)$; however, it was increased in the simvastatin + LPS group compared with the LPS group $(p<0.01)$ (Fig. 5A-D). There were no differences in the levels of TNF- $\alpha$, IL-10, and HIF- $1 \alpha$ in the LPS and simvastatin + LPS groups $(p>0.05)$ (Table I).

\section{TBARS}

TBARS levels were significantly increased in the LPS group compared with the other groups $(p<0.01)$. In the simvastatin + LPS group, TBARS levels were found to be the same as in the control group $(p>0.05)$ (Fig. 6).

\section{Mitochondrial enzyme activity}

There were no changes in the activities of citrate synthase, complex I, complex II, complex I + III, and complex II + III in tissue homogenate $(p>0.05)$ (Table II).

\section{Discussion}

We aimed to investigate the effect of pretreatment with simvastatin on the early phases of sepsis induced by LPS ( $20 \mathrm{mg} / \mathrm{kg}$ i.p., $4 \mathrm{~h})$ in the kidney tissue of rats, which is known to have 

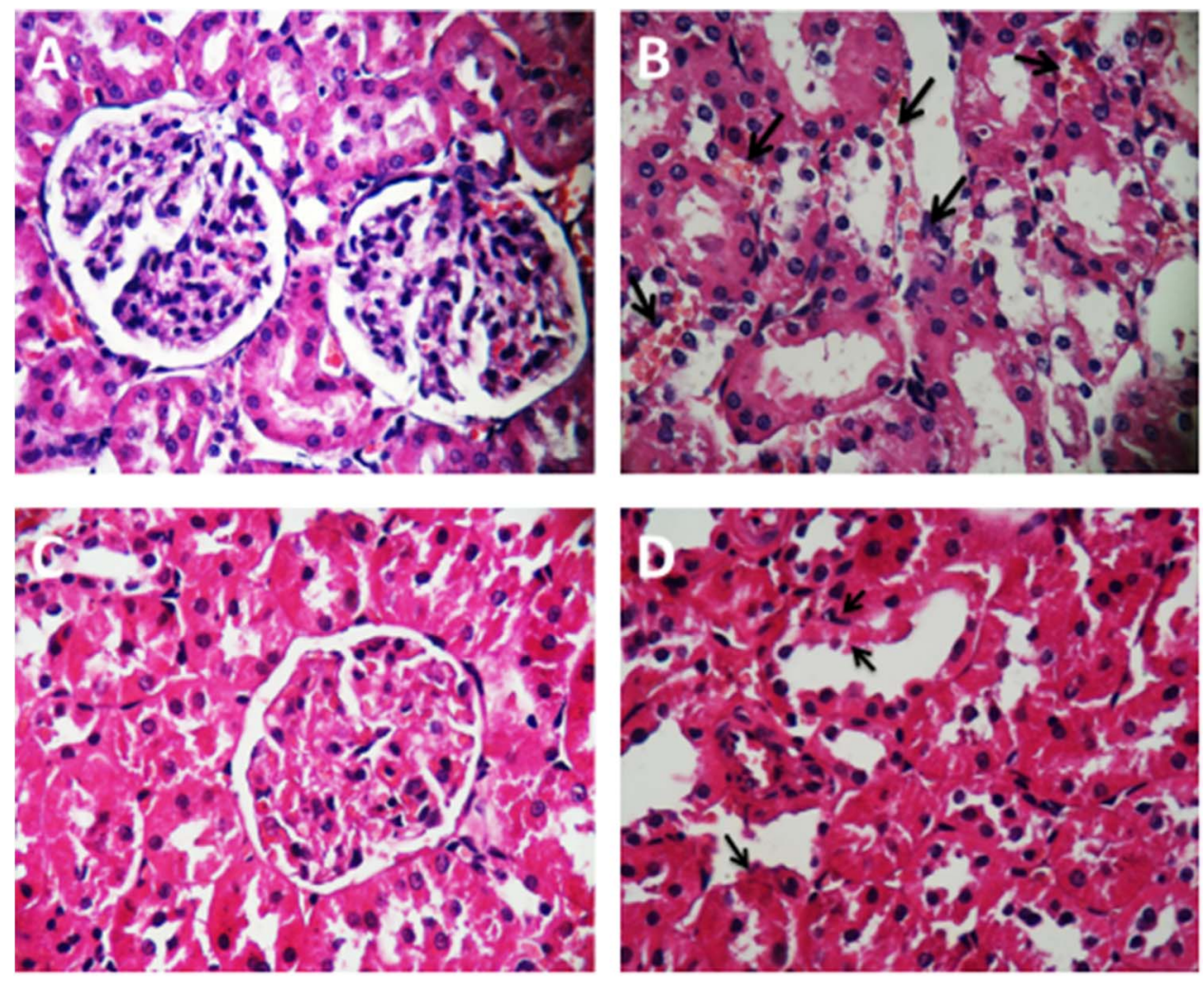

Fig. 1. Section of kidney tissue from the control group stained with H\&E, 40× magnification (A). Section of kidney

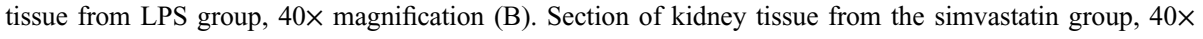
magnification (C). Section of kidney tissue from the simvastatin + LPS group, 40× magnification (D). The arrows show tubular damage in $\mathrm{B}$ and $\mathrm{D}$ sections

an important role in drug clearance. Sepsis is a common cause of acute renal failure and accounts for up to $60 \%$ of cases in clinical studies (40).

In this study, we evaluated the changes of histological appearance, immunohistochemistries of cytokines, HIF-1 $\alpha$, and ghrelin, mitochondrial enzyme activities, and TBARS levels of kidney tissue in the first hours of sepsis. Although TNF- $\alpha$ was found to be significantly higher, there was slightly increased IL-10 immunoreactivity in tissue sections in the LPS and simvastatin + LPS groups compared with that of the controls.

In our previous study, we showed that serum TNF- $\alpha$ and IL-10 levels were significantly higher in the simvastatin + LPS and LPS groups compared with controls. In addition, according to immunohistochemical findings, the levels of TNF- $\alpha$ and IL-10 were higher in the liver tissue of these groups (41).

The kidneys are the most important catabolic organs in the clearance of plasma cytokines. Cytokines and their degradation products are detectable in urine, and in nephrectomized rats, the half-life of cytokines is dramatically increased (27). TNF- $\alpha$ is an important mediator of the systemic and renal effects of sepsis. Continuous intravenous infusion of TNF- $\alpha$ into rabbits produced endothelial cell damage and accumulation of neutrophils in the glomerular capillary lumen, suggesting a chemotactic and/or toxic role for TNF- $\alpha$ in vivo (4). 

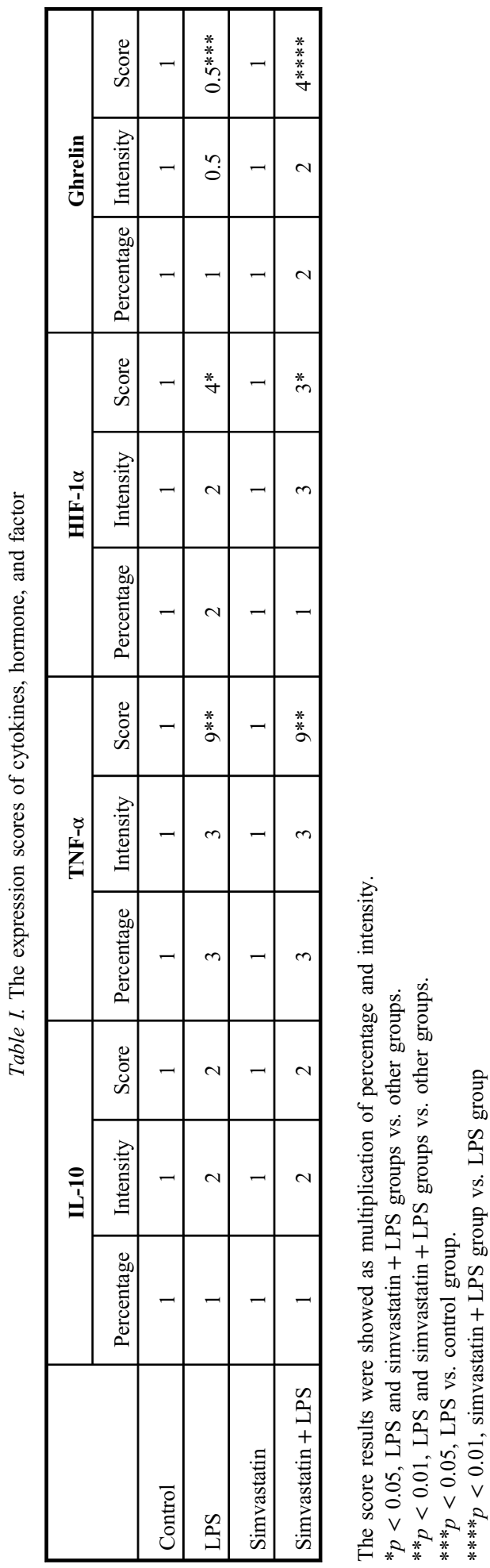


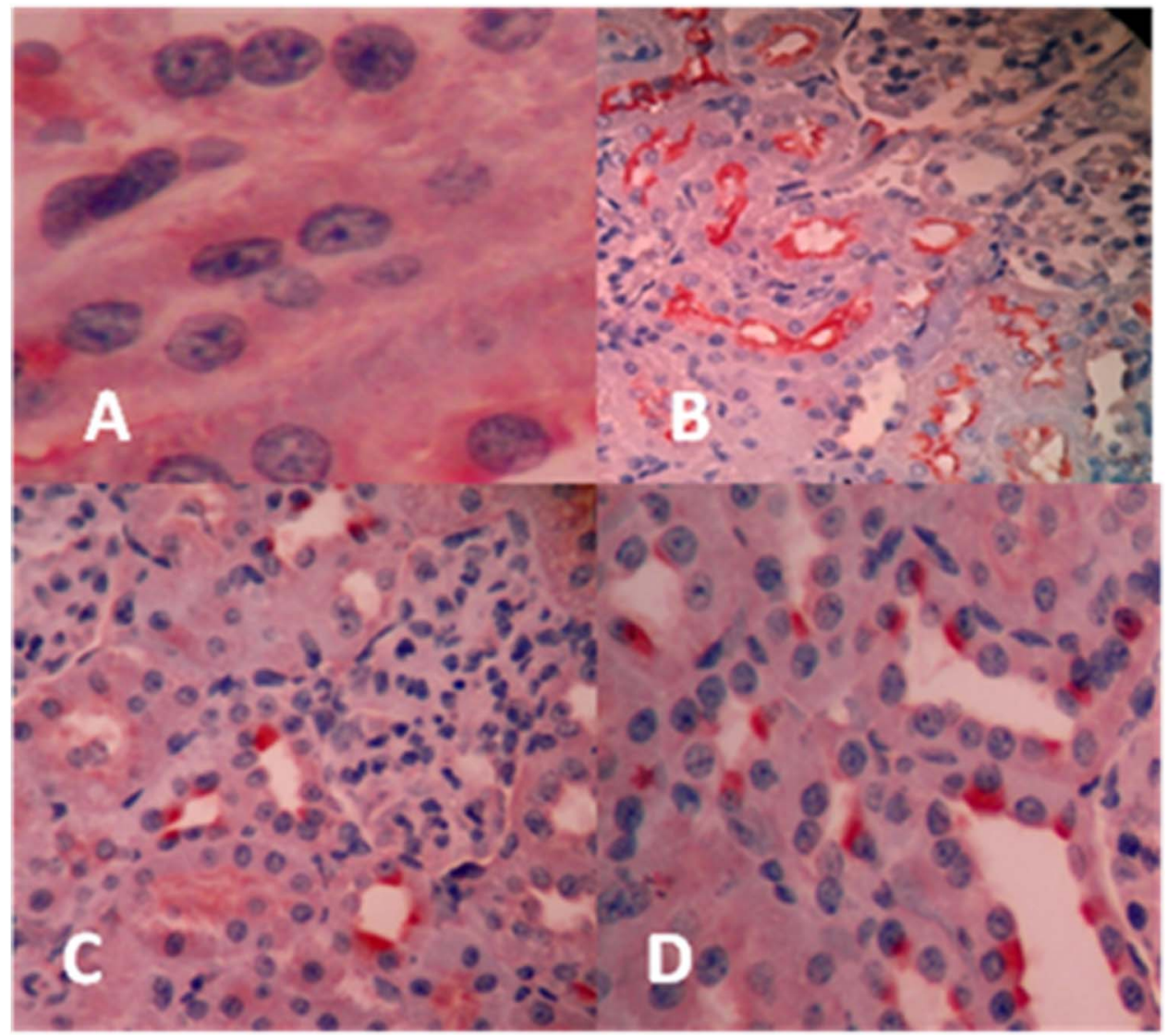

Fig. 2. Immunohistochemical staining of kidney sections for TNF- $\alpha$. Section of kidney tissue from the control group (A), LPS group (B), simvastatin group (C), and simvastatin + LPS group (D)

We observed the dilatation of tubule lumens in the LPS group and partial damage to epithelial cells. In the literature, there are many studies in which histological changes in the kidney tissue of rat have been demonstrated (37).

A controlled study revealed that pretreatment with statins was associated with a reduction of severe sepsis and intensive care unit admission (2). In this study, 5 days of oral simvastatin had no effect on kidney tissue injury, tubule dilatation, or damage in proximal cells in the LPS-treated rats. The failure to prevent tissue damage in the simvastatin + LPS group may be explained by non-reduction of cytokine levels. Yasuda et al. (38) demonstrated that priorly administered simvastatin decreased the cecal ligation and puncture (CLP) induced renal dysfunction at $24 \mathrm{~h}$, but not $6 \mathrm{~h}$ after CLP. They hypothesized that simvastatin might have influence on the late phase of CLP-induced vascular effects. In addition, there were studies which found no effect of simvastatin using either clinical (35) or experimental sepsis model (1).

In sepsis, the interaction of cellular hypoxia with microorganisms and the host immune system contributes to the formation of ROS, which results in oxidative damage of the kidney (3). 


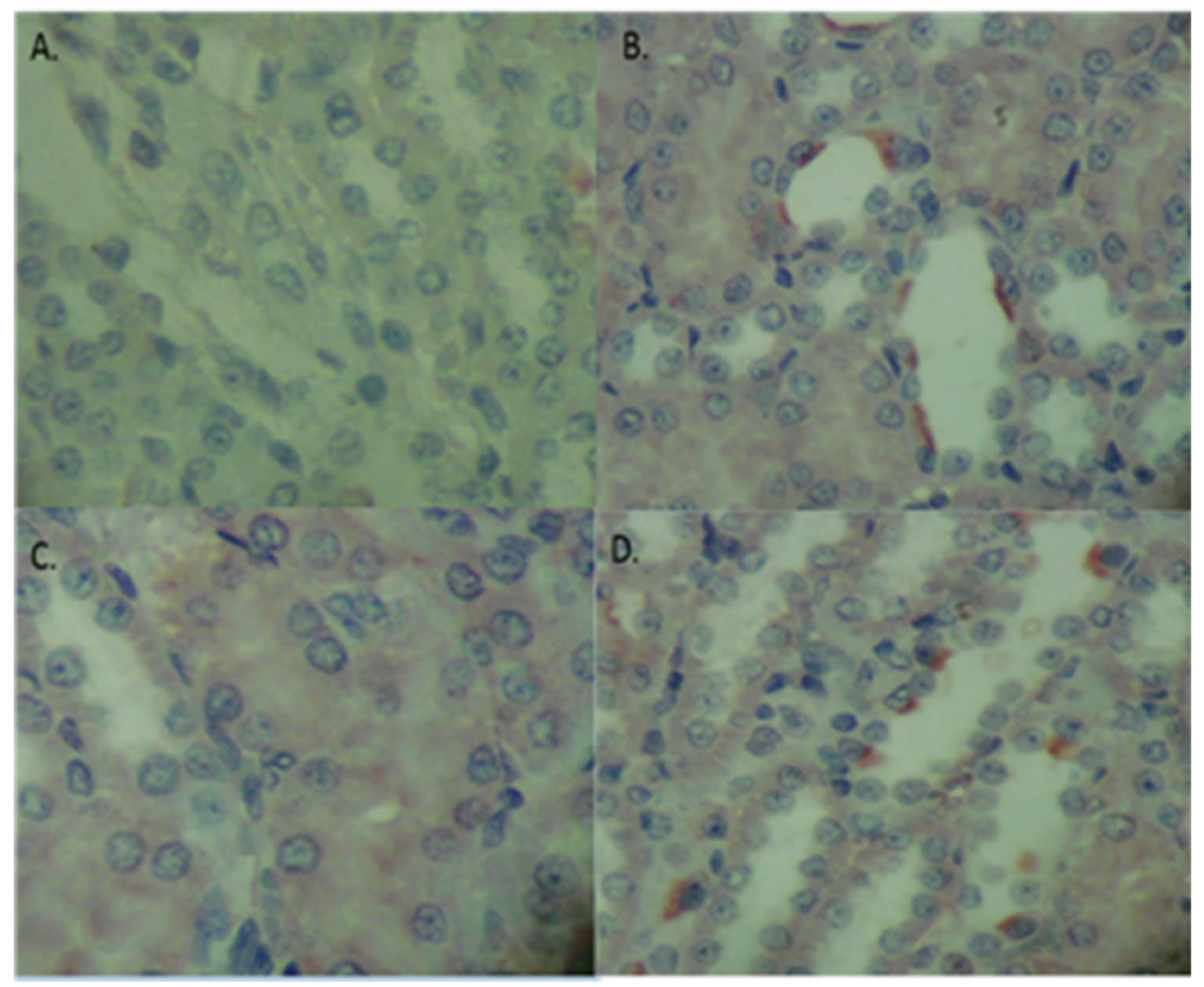

Fig. 3. Immunohistochemical staining of kidney sections for HIF-1 $\alpha$. Section of kidney tissue from the control group (A), LPS group (B), simvastatin group (C), and simvastatin + LPS group (D)

Santos et al. (30) reported that the sepsis group showed increased TBARS through the formation of ROS in the cecal puncture ligation group. In this study, we found increased TBARS levels of kidney tissue in the sepsis group; TBARS levels were reduced in the simvastatin-treated sepsis group compared with those of the LPS group. Iseri et al. (14) showed that treatment with simvastatin-ameliorated nephrotoxicity and reversed renal function by increasing the level of antioxidant enzymes. Teshima et al. (34) demonstrated that statin treatment revealed decreased ROS and subsequent improvement in renal function in an in vivo ischemic AKI model.

The anti-inflammatory effects of ghrelin have also been shown to inhibit sympathetic activation, which is known to be increased in sepsis and endotoxemia (36). Serum ghrelin levels have been reported to be decreased or increased after LPS injection depending on the timing of disease course $(13,19)$. Compared with controls, ghrelin immunoreactivity decreased in the LPS group; however, it increased in the simvastatin + LPS group compared with the LPS group. There were increased HIF-1 $\alpha$ levels in the LPS and simvastatin + LPS groups compared with the controls. We found that the results of immunoreactivities of ghrelin and HIF-1 $\alpha$ levels were similar to the results obtained in liver tissue in our previous study (39). LPS can trigger HIF-1 $\alpha$ activation in macrophages and this is crucial for the development of a LPS-triggered sepsis (12). LPS raises levels of HIF-1 $\alpha$ in macrophages through 


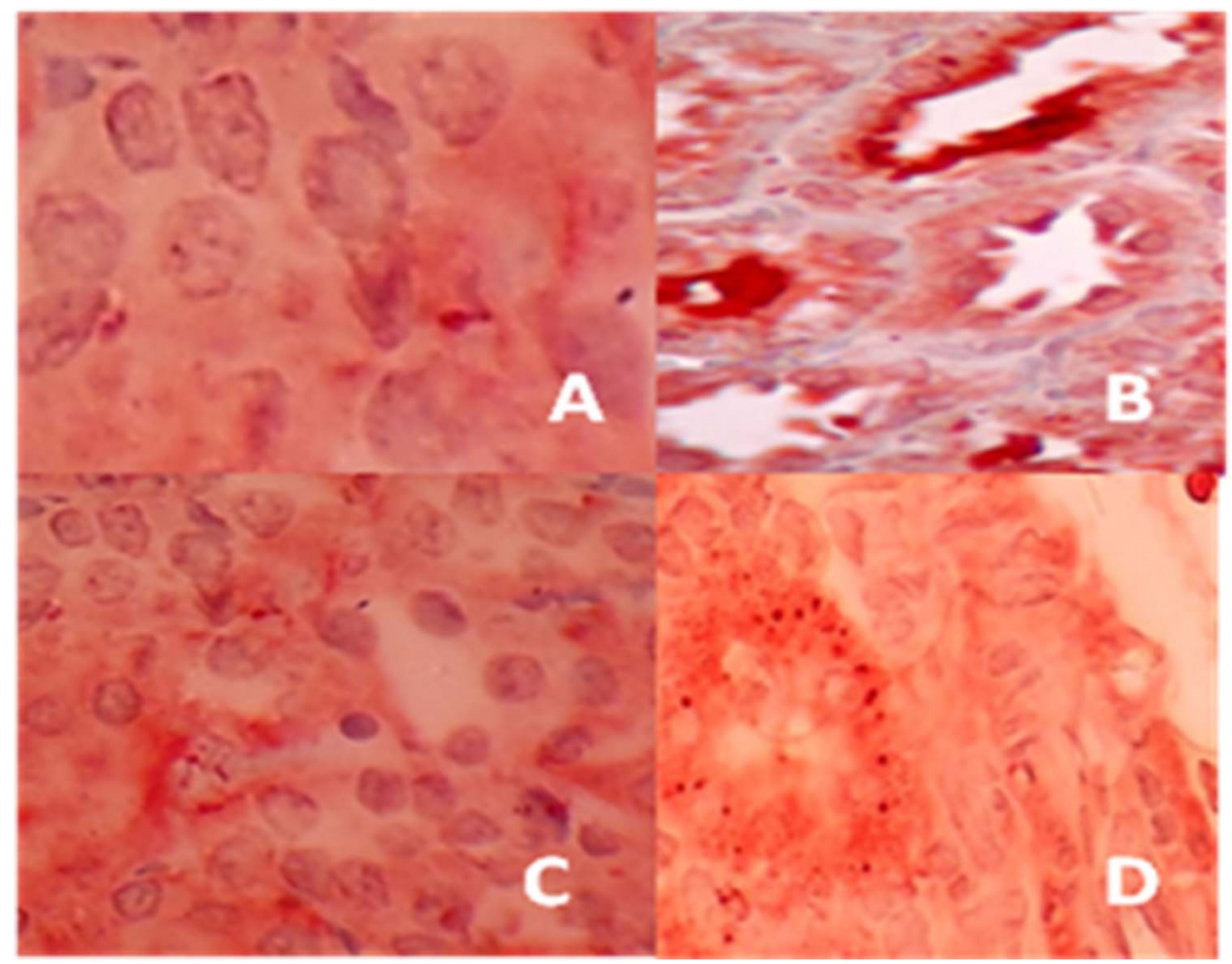

Fig. 4. Immunohistochemical staining of kidney sections for IL-10. Section of kidney tissue from the control group (A), LPS group (B), simvastatin group (C), and simvastatin + LPS group (D)

activating the $\mathrm{p} 42 / 44 \mathrm{MAPK}$ and NfkB signal transduction pathways (26). HIF-1 $\alpha$ induction in macrophages promotes the production of inflammatory cytokines, including TNF- $\alpha$ and IL-1; deletion of HIF- $1 \alpha$ is protective against LPS-induced sepsis in rats (17). In a previous study, although we found alterations in mitochondrial enzyme activity and morphology in muscle, no alterations in the activities of mitochondrial enzymes were observed in the kidney tissue of rats treated with LPS, similar to our previous study in the liver $(24,39)$.

In the literature, there are a number of studies about investigating experimental sepsis rat models with different approaches using different exposure times and dosages of LPS. Consequently, the results are conflicting. In our applied model, in consistence with literature findings $(10,11,20,28)$, the cause of mitochondrial enzyme activity results is depending on exposure time and dosage of LPS in kidney tissue. In the literature, during the early phase of exposure time of LPS; namely, the first $4 \mathrm{~h}$ after injection of LPS, mitochondrial oxidative phosphorylation has been supporting ATP synthesis and cellular energy. In a recent study, Porta et al. (28) have reported that mitochondrial function was not impaired by endotoxin infusion in kidney tissue. Therefore, our results showing unchanged mitochondrial enzyme activities are in accordance with other studies.

LPS has been shown by other authors to elicit alterations in mitochondrial function in rats and subcellular fractions. Decreased mitochondrial enzyme activity of the cells was dependent upon the exposure time and dosage of LPS. This decrease was correlated with 


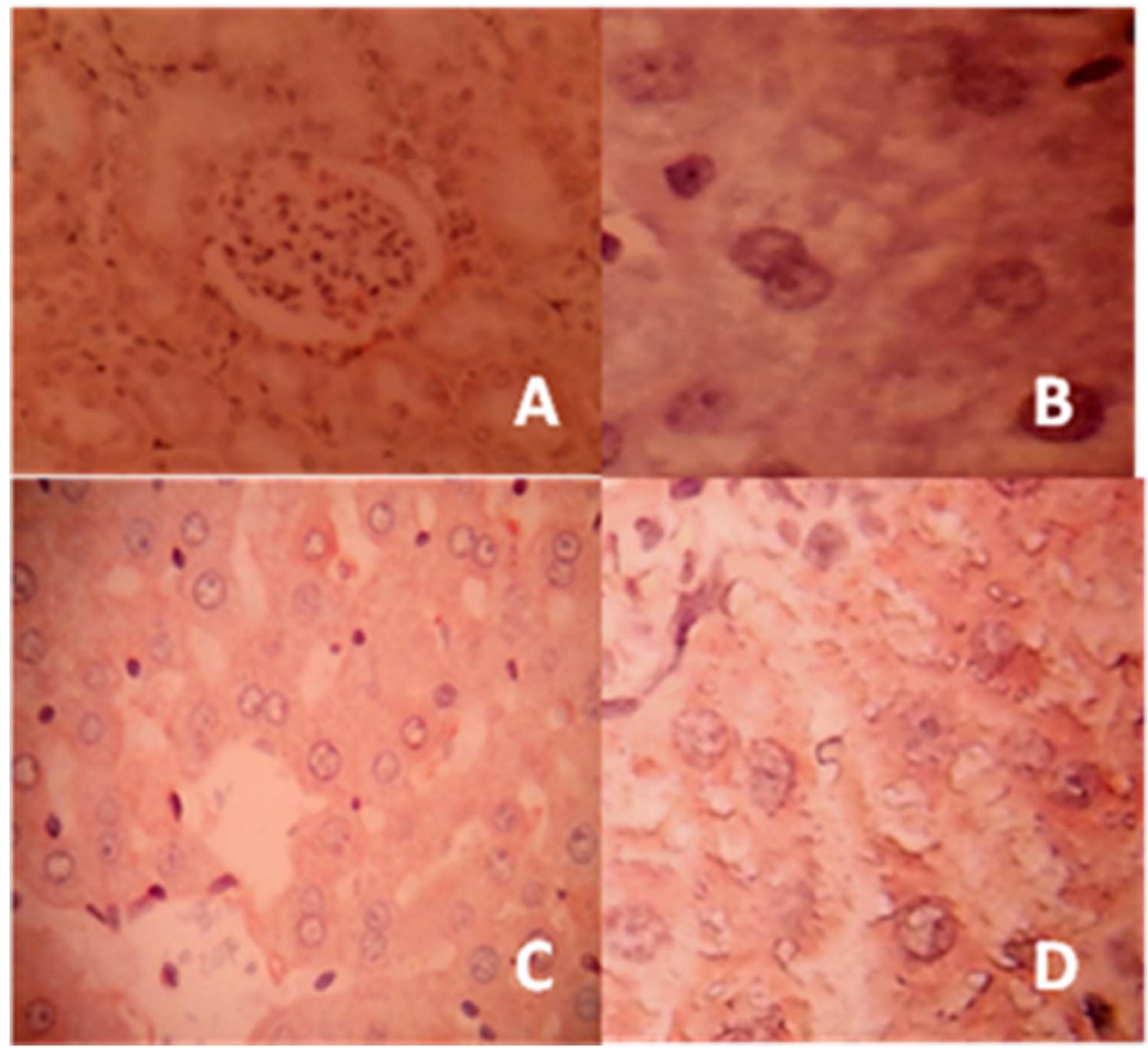

Fig. 5. Immunohistochemical staining of kidney sections for ghrelin. Section of kidney tissue from the control group (A), LPS group (B), simvastatin group (C), and simvastatin + LPS group (D)

TBARS (nmol/g tissue)

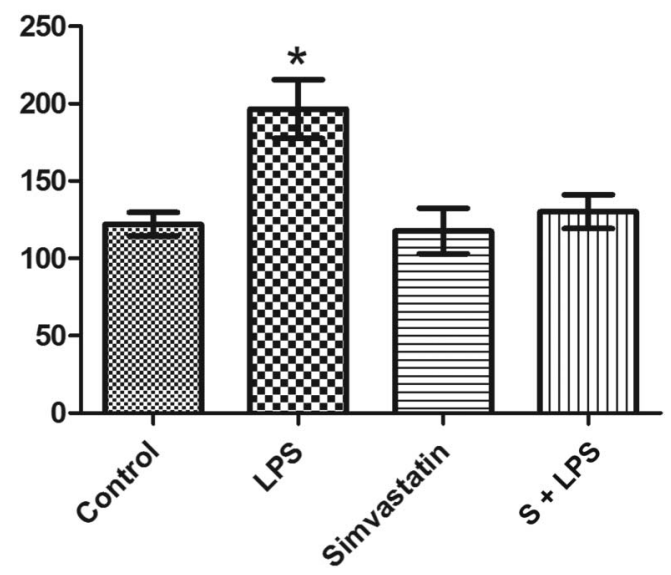

Fig. 6. TBARS in experimental groups. ${ }^{*} p<0.01$, LPS group vs. control, simvastatin, simvastatin + LPS groups 
Table II. Complex I, citrate synthase, I-III, II-III enzymes activities of experimental groups in kidney tissues

\begin{tabular}{|l|c|c|c|c|}
\hline $\begin{array}{l}\text { Mitochondrial } \\
\text { enzyme activity } \\
(\boldsymbol{\mu} \mathbf{m o l} / \mathbf{m i n} / \mathrm{g} \text { tissue })\end{array}$ & Control & LPS & Simvastatin & Simvastatin + LPS \\
\hline Complex I & $26.56 \pm 6.95$ & $30.07 \pm 4.69$ & $29.24 \pm 12.33$ & $23.56 \pm 5.427$ \\
\hline Citrate synthase & $2.331 \pm 0.19$ & $2.228 \pm 0.74$ & $1.763 \pm 0.48$ & $1.805 \pm 0.37$ \\
\hline Complex I-III & $2.457 \pm 1.26$ & $2.332 \pm 0.90$ & $2.88 \pm 2.11$ & $2.529 \pm 0.89$ \\
\hline Complex II-III & $0.19 \pm 0.04$ & $0.24 \pm 0.09$ & $0.18 \pm 0.04$ & $0.17 \pm 0.04$ \\
\hline
\end{tabular}

leakage of enzyme activity from the mitochondrial fraction. It has been reported that mitochondrial oxygen consumption in the liver was either decreased or not affected (21). To our knowledge, no other study has investigated mitochondrial enzyme activities in kidney tissue in parallel with an LPS-induced sepsis model.

Although we found that, in the LPS group, there was dilatation of tubular lumens and partial damage to the epithelial cells in histological sections, there was no damage at the mitochondrial level.

In this study, simvastatin was observed to increase ghrelin levels and decrease TBARS in the kidney tissues of the simvastatin + LPS group; however, the effect of simvastatin may not be sufficient to protect against the damage of sepsis in this early-phase sepsis model.

\section{Acknowledgements}

This study was granted from Istanbul University Research Projects (Project No.: 28773). The authors would like to thank Mr. David F. Chapman for editing of English.

\section{REFERENCES}

1. Altunal C, Agalar F, Agalar C, Daphan C, Saygun O, Aydinuraz K, Sahiner T, Atasoy P, Caglayan O, Dom S: The effect of simvastatin on pulmonary damage in experimental peritonitis in rats. Indian J. Surg. 77(Suppl. 2), S370-S375 (2015)

2. Ando H, Takamura T, Ota T, Nagai Y, Kobayashi K: Cerivastatin improves survival of mice with lipopolysaccharide-induced sepsis. J. Pharmacol. Exp. Ther. 294, 1043-1046 (2000)

3. Andrades ME, Morina A, Spasić S, Spasojević I: Bench-to-bedside review: sepsis-from the redox point of view. Crit. Care 15(5), 230 (2011)

4. Bertani T, Abbate M, Zoja C, Corna D, Perico N, Ghezzi P, Remuzzi G: Tumor necrosis factor induces glomerular damage in the rabbit. Am. J. Pathol. 134, 419-430 (1989)

5. Buege JA, Aust SD: Microsomal lipid peroxidation methods. Methods Enzymol. 52, 302-310 (1978)

6. Chvojka J, Sýkora R, Karvunidis T, Raděj J, Kroužecký A, Novák I, Matějovič M: New developments in septic acute kidney injury. Physiol. Res. 59, 859-869 (2010)

7. Cunningham PN, Dyanov HM, Park P, Wang J, Newell KA, Quigg RJ: Acute renal failure in endotoxemia is caused by TNF acting directly on TNF receptor-1 in kidney. J. Immunol. 168, 5817-5823 (2002)

8. Frede S, Stockmann C, Freitag P, Fandrey J: Bacterial lipopolysaccharide induces HIF-1 activation in human monocytes via p44/42 MAPK and NF-кB. Biochem. J. 396, 517-527 (2006)

9. Fukuzumi M, Shinomiya H, Shimizu Y, Ohishi Y, Utsumi S: Endotoxin-induced enhancement of glucose influx into murine peritoneal macrophages via GLUT1. Infect. Immun. 64, 108-112 (1996)

10. Garrison RN, Ratcliffe DJ, Fry DE: The effects of peritonitis on murine renal mitochondria. Adv. Shock Res. 7, 71-76 (1982) 
11. Geller ER, Jankauskas S, Kirkpatrick J: Mitochondrial death in sepsis: a failed concept. J. Surg. Res. 40, 514517 (1986)

12. Hataya Y, Akamizu T, Hosoda H, Kanamoto N, Moriyama K, Kangawa K, Takaya K, Nakao K: Alterations of plasma ghrelin levels in rats with lipopolysaccharide-induced wasting syndrome and effects of ghrelin treatment on the syndrome. Endocrinology 144, 5365-5371 (2003)

13. Inoue T, Saito H, Fukushima R, Inaba T, Lin MT, Fukatsu K, Muto T: Growth hormone and insulin like growth factor I enhance host defense in a murine sepsis model. Arch. Surg. 130, 1115-1122 (1995)

14. Işeri S, Ercan F, Gedik N, Yüksel M, Alican I: Simvastatin attenuates cisplatin-induced kidney and liver damage in rats. Toxicology 230(2-3), 256-264 (2007)

15. Jaber BL: The cytokine network in acute renal failure. Nephrol. Rounds 3, 31-36 (2005)

16. Jeger V, Djafarzadeh S, Jakob SM, Takala J: Mitochondrial function in sepsis. Eur. J. Clin. Invest. 43, 532-542 (2013)

17. Kim HY, Kim YH, Nam BH, Kong HJ, Kim HH, Kim YJ, An WG, Cheong J: HIF-1 $\alpha$ expression in response to lipopolysaccaride mediates induction of hepatic inflammatory cytokine TNF $\alpha$. Exp. Cell Res. 313, 1866-1876 (2007)

18. King TE, Howard RL: Preparation and properties of soluble NADH dehydrogenase from cardiac muscle. Methods Enzymol. 10, 275-294 (1967)

19. Liao W, Rudling M, Angelin B: Contrasting effects of growth hormone and insulin-like growth factor I on the biological activities of endotoxin in the rat. Endocrinology 138, 289-295 (1997)

20. Mason KE, Stofan DA: Endotoxin challenge reduces aconitase activity in myocardial tissue. Arch. Biochem. Biophys. 469, 151-156 (2008)

21. McGivney A, Bradley SG: Action of bacterial endotoxin and lipid A on mitochondrial enzyme activities of cells in culture and subcellular fractions. Infect. Immun. 25, 664-671 (1979)

22. McGuigan PJ, O'Kane CM, McAuley DF: Benefits of statins in the critically ill: promising but not proven. Crit. Care Med. 39, 1599-1600 (2011)

23. Ota T, Ota K, Jono H, Fujimori H, Ueda M, Shinriki S, Sueyoshi T, Shinohara M, Ando Y: Midkine expression in malignant salivary gland tumors and its role in tumor angiogenesis. Oral Oncol. 46, 657-661 (2010)

24. Ozkok E, Yorulmaz H, Ates G, Serdaroglu-Oflazer P, Tamer AS: Effects of prior treatment with simvastatin on skeletal muscle structure and mitochondrial enzyme activities during early phases of sepsis. Int. J. Clin. Exp. Pathol. 7, 8356-8365 (2014)

25. Panichi V, Paoletti S, Mantuano E, Manca-Rizza G, Filippi C, Santi S, Taccola D, Donadio C, Tramonti G, Innocenti M, Casto G, Consani C, Sbragia G, Franzoni F, Galetta F, Panicucci E, Barsotti G: In vivo and in vitro effects of simvastatin on inflammatory markers in pre-dialysis patients. Nephrol. Dial. Transplant. 21, 337-344 (2006)

26. Peyssonnaux C, Cejudo-Martin P, Doedens A, Zinkernagel AS, Johnson RS, Nizet V: Cutting edge: essential role of hypoxia inducible factor- $1 \alpha$ in development of lipopolysaccharide-induced sepsis. J. Immunol. 178, 7516-7519 (2007)

27. Poole S, Bird TA, Selkirk S, Gaines-Das RE, Choudry Y, Stephenson SL, Kenny AJ, Saklatvaa J: Fate of injected interleukin1 in rats: sequestration and degradation in the kidney. Cytokine 2, 416-422 (1990)

28. Porta F, Takala J, Weikert C, Bracht H, Kolarova A, Lauterburg BH, Borotto E, Jakob SM: Effects of prolonged endotoxemia on liver, skeletal muscle and kidney mitochondrial function. Crit. Care 10, R118 (2006)

29. Russo MW, Scobey M, Bonkovsky HL: Drug-induced liver injury associated with statins. Semin. Liver Dis. 29, 412-422 (2009)

30. Santos Fdo N, Watanabe M, Vasco CF, Fonseca CD, Vattimo Mde F: Antioxidant protection of statins in acute kidney injury induced by sepsis. Rev. Esc. Enferm. USP 48(5), 820-826 (2014)

31. Scottocosa GL, Kuylenstierna B, Ernster L, Bergstrand A: An electron transport system associated with the outer membrane of the mitochondria. J. Cell Biol. 32, 415-438 (1967)

32. Singer M, Brealey D: Mitochondrial dysfunction in sepsis. Biochem. Soc. Symp. 66, 149-166 (1999)

33. Slotta JE, Laschke MW, Schilling MK, Menger MD, Jeppsson B, Thorlacius H: Simvastatin attenuates hepatic sensitization to lipopolysaccharide after partial hepatectomy. J. Surg. Res. 162, 184-192 (2010)

34. Teshima CAS, Dezoti C, Watanabe M, Vattimo MFF: A estatina e a lesão renal aguda isquêmica em ratos [Statin and acute ischemic renal injury in rats]. Acta Paul. Enferm. 25(1), 86-89 (2012)

35. Viasus D, Garcia-Vidal C, Simonetti AF, Dorca J, Llopis F, Mestre M, Morandeira-Rego F, Carratalà J: The effect of simvastatin on inflammatory cytokines in community acquired pneumonia: a randomised, double-blind, placebo-controlled trial. BMJ Open 5, e006251 (2015) 
36. Wu R, Dong W, Cui X, Zhou M, Simms HH, Ravikumar TS, Wang P: Ghrelin down-regulates proinflammatory cytokines in sepsis through activation of the vagus nerve. Ann. Surg. 245, 480-486 (2007)

37. Xu C, Chang A, Hack BK, Eadon MT, Alper SL, Cunningham PN: TNF-mediated damage to glomerular endothelium is an important determinant of acute kidney injury in sepsis. Kidney Int. 85, 72-81 (2014)

38. Yasuda H, Yuen PST, Hu X, Zhou H, Star RA: Simvastatin improves sepsis-induced mortality and acute kidney injury via renal vascular effects. Kidney Int. 69, 1535-1542 (2006)

39. Yorulmaz H, Ozkok E, Erguven M, Ates G, Aydın I, Tamer S: Effect of simvastatin on mitochondrial enzyme activities, ghrelin, hypoxia-inducible factor $1 \alpha$ in hepatic tissue during early phase of sepsis. Int. J. Clin. Exp. Med. 8, 3640-3650 (2015)

40. Young L (1995): Sepsis syndrome. In: Principles and Practice of Infectious Diseases, eds Mandel G, Bennet J, Dolin R, Churchill Livingston, New York, pp. 690-705

41. Zarjou A, Agarwal A: Sepsis and acute kidney injury. J. Am. Soc. Nephrol. 22, 999-1006 (2011)

42. Zinkernagel AS, Johnson RS, Nizet U: Hypoxia inducible factor (HIF) function in innate immunity and infection. J. Mol. Med. (Berl.) 85, 1339-1346 (2007) 